\title{
Effect of beef from grass or maize silage- and concentrate-fed cattle on lipid metabolism and antioxidative status of rats
}

\author{
A. Łozicki ${ }^{1}$ and M. Dymnicka \\ Warsaw University of Life Sciences, SGGW, Department of Animal Nutrition and Feed Management \\ Ciszewskiego 8, 02-787 Warsaw, Poland
}

KEY WORDS: maize silage, grass,, lipid metabolism, oxidative status, beef, rats

Received: 21 March 2013

Revised: 7 January 2014

Accepted: 11 March 2014

${ }^{1}$ Corresponding author:

e-mail: andrzej_lozicki@sggw.pl

\begin{abstract}
In comparison with concentrate-fed animals, grass-fed cattle provides meat with a higher level of desired polyunsaturated $n-3$ fatty acids and compounds with antioxidative effects, e.g., a-tocopherol and $\beta$-carotene. This should be reflected in a positive influence on fat metabolism and antioxidative status of the consumer's organism. There are no studies, however, where the effect of beef obtained from a specified fattening system on lipid metabolism and antioxidative status of the consumer has been analysed. The objective of this study was to compare the influence of beef obtained from grass-fed bulls and from silage/concentrate-fed animals on the lipid metabolism and antioxidant status of rats. In a study conducted for 6 weeks, the rats received AIN93G-based diets containing lyophilized beef from animals fattened intensively with maize silage and concentrates (group S/C-B) or fed extensively with grass (group G-B). The meat constituted $20 \%$ of diet and was the only source of protein and fat. The rats from the control group received a meatless AIN-93based diet (CO) with casein and rapeseed oil. The lowest concentrations of triglycerides (TAG), total cholesterol and very-low-density lipoprotein (VLDL) were found in the control group receiving vegetable oil. No effect of kind of meat on the selected parameters of lipid metabolism was recorded. Determination of indicators of antioxidative status revealed that the highest concentration of glutathione peroxidase was found in the serum of rats from group G-B. The livers of the animals from this group also had the highest concentration of a-tocopherol and the lowest of thiobarbituric acid-reactive substances (TBARS). In summary, we can state that the meat from the grass-fed animals, as compared with that from intensively fattened bulls, positively affected most of the examined antioxidative status indicators in rats. No effect of the meat on indicators of lipid metabolism was found.
\end{abstract}

\section{Introduction}

Due to its high content of saturated fatty acids and cholesterol, beef, a red meat, is perceived as a product enhancing the risk of hypercholesterolaemia and cardiovascular diseases (Fraser, 1999; Hu et al., 1999; Barton et al., 2007; Kontogianni et al., 2008).
Although the consumption of red meat has several disadvantages, there are also advantages. The lipid fraction of beef is a source of health-promoting components, including $\alpha$-linolenic acid (ALA), conjugated linoleic acid (CLA), eicosapentaenoic acid (EPA), docosapentaenoic acid (DPA) and docosahexaenoic acid (DHA) (Razminowicz et al., 2006; 
McAfee et al., 2010). The contents of these compounds in beef is enhanced by pasture feeding. Compared with nutrition using large amounts of concentrates, it also ensures higher contents of antioxidants such as $\alpha$-tocopherol or $\beta$-carotene (Simonne et al., 1996; Yang et al., 2002; De la Fuente, 2009; Łozicki et al., 2012). Some studies in humans demonstrate the influence of fatty acids, vitamins, trace elements, and other bioactive compounds when administered as dietary supplements on lipid metabolism and antioxidant status (Sies, 1997; McAfee et al, 2011).

In most studies evaluating the effect of beef on consumer health, the employed nutrition system of fattened cattle is not considered. It is, however, the factor that, due to the chemical composition of the meat, seems to be significant from the consumer's viewpoint. The presented study also focuses on the influence of beef on lipid metabolism. There is a lack of studies considering the effects of beef originating from different fattening systems on the antioxidative status of the consumer's organism.

When evaluating beef from grass-fed cattle as compared with that from animals fed great quantities of concentrates, we may suppose that the higher content of polyunsaturated n-3 fatty acids desired in the human diet should have a favourable effect on lipid metabolism in the body. Moreover, the higher level of antioxidants in the discussed meat should also positively affect the antioxidative status of the consumer's organism.

Although the chemical composition of beef originating from different feeding regimes differs significantly, the biological effects of the consumed meat have to be evaluated on the level of the consumer's organism, because all biomolecules present in meat are transformed and metabolized within the consumer's body.

Thus, the objective of this study was to compare the influence of beef from grass-fed animals and that from silage/grain-fed bulls on the lipid metabolism and antioxidant status of rats as a model for humans.

\section{Material and methods}

\section{Experimental animals - housing and feeding}

The study was carried out following the procedures approved by the Local Ethics Commission for experiments with animals.

The experiment was conducted on 30 growing Wistar rats with an initial body weight of $108 \mathrm{~g}$. The animals were randomly assigned to 3 experimental groups, 10 rats each. The rats were housed in individual cages with a 12-h light-dark cycle, temperature of $22^{\circ} \mathrm{C}$ and humidity of $50 \%-60 \%$. The experiment lasted 6 weeks. The animals had free access to feed and water. They all were fed semipurified AIN-93G-based diets (Reeves, 1997). Two groups of rats were fed AIN-93G-based diets with beef originating from animals fed in the extensive fattening system with grass (group G-B) and in the intensive fattening system with maize silage and concentrates (group S/C-B). After lyophilization and comminution, meat was added in an amount of $20 \%$ to the diets. Rats from the control group (CO) were fed AIN-93G-based diets without meat. In the groups that received meat, it was the only source of protein and fat in the diet. In the group fed the meatless diet, the source of protein was casein, that of fat, rapeseed oil (Table 1). All diets were isoproteinous and had a similar level of fat.

Table 1. Composition and nutritive value of experimental diets

\begin{tabular}{lccc}
\hline \multirow{2}{*}{ Indices } & Group & & \\
\cline { 2 - 5 } & $\mathrm{CO}$ & $\mathrm{G}-\mathrm{B}$ & $\mathrm{S} / \mathrm{C}-\mathrm{B}$ \\
\hline Ingredients, $\mathrm{g} \cdot \mathrm{kg}^{-1}$ diet & & & \\
$\quad$ beef - grass feeding & - & 200 & - \\
beef - maize silage and concentrate feeding & - & - & 200 \\
casein & 197 & - & - \\
starch & 689 & 711 & 711 \\
cellulose & 40 & 40 & 40 \\
rapeseed oil & 25 & - & - \\
${ }^{*}$ AIN-93G Mineral Mix & 35 & 35 & 35 \\
**AIN-93-VX Vitamin Mix & 10 & 10 & 10 \\
choline chloride & 2 & 2 & 2 \\
methionine & 2 & 2 & 2 \\
In kg of mixture, g & & & \\
dry matter & 904 & 911 & 906 \\
crude ash & 28.3 & 31.4 & 32.9 \\
crude protein & 163.6 & 166.5 & 162.2 \\
crude fat & 24.7 & 17.4 & 23.4 \\
\hline
\end{tabular}

CO - control diet; G-B - diet with beef from grass feeding; S/C-B - diet with beef from feeding with maize silage and concentrate; *AIN-93G Mineral Mix (No. 94046), ${ }^{* *}$ AIN-93-VX Vitamin Mix (No.94047)

\section{Meat characteristics}

Beef was obtained from Hereford bulls fed, in the finishing diet, with maize silage and concentrate (intensive feeding) or grass (extensive feeding). Intensively fattened young bulls were fed ad libitum maize silage that was supplemented with a small amount of hay and with concentrate (silage/concentrate-fed bulls). The mean quantity of concentrate in the diets during the fattening period was $4 \mathrm{~kg}$ per animal. In the extensive fattening, in winter the young bulls were fed ad libitum with grass silage, a small quantity of hay and concentrate, on average $2 \mathrm{~kg}$ of concentrate per animal. After the period of winter feeding, the bulls were fattened on pasture for 4 months and after that slaughtered (Łozicki et 
al., 2012). During the pasture feeding, grass was the only feed of the fattened bulls (grass-fed animals).

The longissimus thoracis muscle samples were collected $24 \mathrm{~h}$ after slaughter from the half-carcasses of 8 bulls from each fattening system. They were packed in foil bags and frozen at $-20^{\circ} \mathrm{C}$ until analysis and the experiment on rats. Before commencement of the experiment with the rats, the meat samples of the particular groups were lyophilized, disintegrated and mixed altogether. The prepared meat was then added to the mixtures for the rats. The fat content and fatty acid composition of meat is listed in Table 2 (Łozicki at al., 2012).

Table 2. Chemical composition, fatty acid profile and contents of a-tocopherol and selected minerals in the analysed meat (Łozicki et al., 2012) and rapeseed oil

\begin{tabular}{llll}
\hline Indices & $\begin{array}{l}\text { Beef - } \\
\text { grass } \\
\text { feeding }\end{array}$ & $\begin{array}{l}\text { Beef - maize } \\
\text { silage and con- } \\
\text { centrate feeding }\end{array}$ & $\begin{array}{l}\text { Rapeseed } \\
\text { oil }\end{array}$ \\
\hline Dry matter, $\mathrm{g} \cdot \mathrm{kg}^{-1}$ & 228 & 231 & - \\
Crude protein, $\mathrm{g} \cdot \mathrm{kg}^{-1}$ & 218.20 & 220.00 & \\
Crude fat, $\mathrm{g} \cdot \mathrm{kg}^{-1}$ & 20.61 & 27.83 & - \\
SFA, \% total fatty acid & 46.864 & 46.485 & 7.35 \\
MUFA, \% total fatty acid & 37.947 & 41.752 & 61.45 \\
PUFA, \% total fatty acid & 12.560 & 9.669 & 28.37 \\
$\Sigma \mathrm{n}-3$ & 3.077 & 1.653 & - \\
$\Sigma \mathrm{n}-6$ & 8.784 & 7.545 & - \\
$\mathrm{n}-6 / \mathrm{n} 3$ & 2.868 & 4.615 & - \\
$\mathrm{a}-\mathrm{Tocopherol}, \mu \mathrm{gg} \cdot \mathrm{g}^{-1}$ & 4.61 & 3.88 & 23.8 \\
$\mathrm{Zn}, \mathrm{mg} \cdot \mathrm{kg}^{-1}$ & 54.9 & 45.6 & - \\
$\mathrm{Cu}, \mathrm{mg} \cdot \mathrm{kg}^{-1}$ & 1.1 & 1.2 & - \\
$\mathrm{Fe}, \mathrm{mg} \cdot \mathrm{kg}^{-1}$ & 37.1 & 29.7 & - \\
$\mathrm{Mn}, \mathrm{mg} \cdot \mathrm{kg}^{-1}$ & 0.87 & 0.92 & -
\end{tabular}

SFA - saturated fatty acids; MUFA - monounsaturated fatty acids; PUFA - polyunsaturated fatty acids

\section{Collection and preparation of blood and liver samples}

The rats were subject to fasting for $12 \mathrm{~h}$ before the termination of the experiment. After anaesthesia (ketamine overdose: $50 \mathrm{mg} \cdot \mathrm{kg}^{-1}$ body weight), blood samples were collected from the left cardiac ventricle into plastic test tubes without an anticoagulant and into test tubes with heparin. To obtain serum and plasma, part of the blood was centrifuged (1500 $\mathrm{rpm}$ for $10 \mathrm{~min})$. The samples were frozen $\left(-70^{\circ} \mathrm{C}\right)$ and stored until analysed. After decapitation of the rats, their livers were dissected and weighed. Liver samples were cooled and frozen at $-70^{\circ} \mathrm{C}$ until analysed for concentrations of $\alpha$-tocopherol and thiobarbituric acid-reactive substances (TBARS).

\section{Analyses}

The chemical composition of the diets was determined according to AOAC methods (2005).
The quantitative determinations of $\alpha$-tocopherol were performed using HPLC conducted with electrochemical detection according to ESA - Application note (Murphy and Kehrer, 1987). One gram of tissue was homogenized and extracted with $5 \mathrm{ml}$ of a hexane:ethanol mixture (50:50) with the addition of $0.01 \%$ butylhydroxyanisole (BHA). The tocopherols were extracted by mixing in a Vortex for 60 min in the dark at about $4^{\circ} \mathrm{C}$ in hermetic vessels. The contents were then centrifuged in an Eppendorf 4250 centrifuge for $10 \mathrm{~min}$ at $11,000 \mathrm{rpm}$ and $4^{\circ} \mathrm{C}$. Afterwards, the hexane phase was collected. The prepared sample $(1 \mathrm{ml})$ was evaporated under gaseous nitrogen and the dry residue was dissolved in $200 \mu \mathrm{l}$ of the mobile phase and then placed in an auto-sampler's carrousel at $4^{\circ} \mathrm{C}$.

Total cholesterol, VLDL cholesterol, HDL cholesterol and triglycerides (TAG) were determined in blood serum by a spectrometric method using a VITROS analyser in a system composed of an EKTAchem DT-60-II with the DT, DTE and DTSC modules, using sets of slides from Johnson and Johnson Clinical Diagnostics.

Glutathione peroxidase (PGx) activity was measured in blood by the modified Kraus and Gather (1980) method. In the presence of glutathione reductase (GR) and NADPH, oxidized glutathione (GSSG) is converted to the reduced form with concomitant oxidation of NADPH to NADP ${ }^{+}$. Absorbance was measured at a wavelength of $340 \mathrm{~nm}$ (Rancel RS 505, Randox, Crumlin, UK). PGx activity was expressed in $\mathrm{U} \cdot \mathrm{ml}^{-1}$ blood, with $1 \mathrm{U}$ corresponding to the oxidation of $1 \mu \mathrm{mol} \mathrm{NADPH} \cdot \mathrm{min}^{-1}$.

The total antioxidative activity of blood plasma (TAS) was determined by a colorimetric method using kits by Randox Laboratories Ltd. and expressed in $\mathrm{mmol} \cdot \mathrm{l}^{-1}$. The results were read out with a Cobra Mira biochemical analyser (Roche) at a wavelength of $600 \mathrm{~nm}$ (Smart et al., 1996).

Malondialdehyde, the most abundant compound of all lipid peroxidation products, was measured using thiobarbituric acid (TBA) according to the Uchiyama and Mihara (1978) technique. Absorbance was measured at a wavelength of $535 \mathrm{~nm}$ with a Tecan Infinite M200 analyser (Tecan Group Ltd., Switzerland). The results represent the concentration of TBARS in the samples. The tissues were homogenized in $1 \%$ potassium chloride and centrifuged at $2000 \mathrm{~g}$ for $15 \mathrm{~min}$ at $4^{\circ} \mathrm{C}$. The supernatant was used for analyses and the tissues were placed in a reaction solution ( $1 \%$ phosphoric acid, $2 \%$ butylated hydroxytoluene, $1 \%$ potassium chloride and $0.4 \%$ TBA). The solution was kept at $95^{\circ} \mathrm{C}$ for 60 min prior to analysis. 


\section{Statistical analysis}

The obtained results were elaborated statistically using one-way analysis of variance with the least square method. The effect of feeding on the analysed parameters was taken into account. The tables contain the mean values of parameters and standard errors of the means. Computations were made with the Statgraphics 6.0 Plus statistical package.

\section{Results}

The mean values for lipid profile indices measured in the blood serum of rats are presented in Table 3. The lowest concentration of TAG, total cholesterol and VLDL was observed in rats fed the control diet (CO group). Intake of the diets by rat from groups $\mathrm{G}-\mathrm{B}$ and $\mathrm{S} / \mathrm{C}-\mathrm{B}$ significantly $(P \leq 0.01)$ increased TAG, and from group $\mathrm{S} / \mathrm{C}-\mathrm{B}$ significantly $(P \leq 0.05)$ increased total cholesterol in comparison with animals fed control diet. There were no significant differences between the rats receiving the mixture with meat from grass-fed animals and from silage/concentrate-fed bulls, nevertheless, some tendencies towards decreasing TAG, total cholesterol and VLDL were recorded for the rats fed beef from grass-fed animals.

The values of parameters reflecting the redox status of the organism, as measured in the serum of rats, are shown in Table 4. There were no significant differences between the rats in activity of glutathione reductase (GR) and total antioxidant status (TAS). Consumption of beef from grass-fed animals in comparison with meat from silage/concentratefed bulls and also the control group influenced the activity of glutathione peroxidase (GPx). As compared with the $\mathrm{CO}$ group, the difference was statistically significant $(P \leq 0.01)$. The concentration of TBARS, a measure of lipid oxidation, was the highest in the rats fed S/C-B and the lowest in the rats from the control as well as G-B groups, however, the differences were not significant.

The concentrations of $\alpha$-tocopherol and TBARS were measured in the liver of rats (Table 5). The highest $(P \leq 0.05)$ concentration of tocopherol was found in the liver of the rats fed the diets containing meat from grass-fed animals in comparison with S/C-B. The highest concentration of TBARS in the liver was noted in group S/C-B in comparison with control groups, but most importantly, also the concentration of this lipid peroxidation marker was significantly lower in the rats fed the beef from grass-fed bulls vs silage/concentrate-fed animals $(P \leq 0.05)$.
Table 3. Concentrations of lipid metabilism markers in blood serum of rats

\begin{tabular}{|c|c|c|c|c|c|}
\hline \multirow{2}{*}{ Indices } & \multicolumn{3}{|c|}{ Group } & \multirow{2}{*}{-SE } & \multirow{2}{*}{$P$-value } \\
\hline & $\overline{\mathrm{CO}}$ & G-B & S/C-B & & \\
\hline Triglycerides (TAG), $\mathrm{mmol} \cdot \mathrm{I}^{-1}$ & $0.89^{\mathrm{A}}$ & $1.08^{B}$ & $1.14^{\mathrm{B}}$ & 0.047 & 0.004 \\
\hline Total cholesterol, $\mathrm{mmol} \cdot \mathrm{l}^{-1}$ & $1.32^{\mathrm{a}}$ & 1.45 & $1.55^{b}$ & 0.057 & 0.022 \\
\hline $\mathrm{HDL}$ cholesterol, $\mathrm{mmol} \cdot \mathrm{l}^{-1}$ & 1.20 & 1.16 & 1.13 & 0.039 & 0.418 \\
\hline VLDL cholesterol, $\mathrm{mmol} \cdot \mathrm{l}^{-1}$ & 0.40 & 0.44 & 0.46 & 0.022 & 0.136 \\
\hline
\end{tabular}

CO - control diet; G-B - diet with beef from grass feeding; S/C-B - diet with beef from feeding with maize silage and concentrate; ${ }^{A B}, \mathrm{ab}$ means with different superscipts within a row are significantly different at $P \leq 0.01$ or $P \leq 0.05$ respectively

Table 4. Levels of selected parameters of the antioxidative status in blood serum and plasma

\begin{tabular}{|c|c|c|c|c|c|}
\hline \multirow{2}{*}{ Indices } & \multicolumn{3}{|c|}{ Group } & \multirow{2}{*}{-SE } & \multirow{2}{*}{$P$-value } \\
\hline & $\overline{\mathrm{CO}}$ & G-B & S/C-B & & \\
\hline Peroxidase (GPx), $\mathrm{U} \cdot \mathrm{ml}^{-1}$ & $0.79^{\mathrm{B}}$ & $0.93^{\mathrm{A}}$ & 0.86 & 0.029 & 0.005 \\
\hline Reductase (GR), $\mathrm{U} \cdot \mathrm{ml}^{-1}$ & 2.47 & 2.38 & 2.41 & 0.044 & 0.341 \\
\hline $\mathrm{TAS}, \mathrm{mmol} \cdot \mathrm{I}^{-1}$ & 1.25 & 1.31 & 1.29 & 0.025 & 0.226 \\
\hline TBARS, nmol $\cdot \mathrm{g}^{-1}$ & 1.03 & 1.06 & 1.16 & 0.049 & 0.164 \\
\hline
\end{tabular}

$\mathrm{CO}$ - control diet; G-B - diet with beef from grass feeding; S/C-B - diet with beef from feeding with maize silage and concentrate; TAS - total antioxidant status; TBARS - thiobarbituric acid-reactive substances; ${ }^{A B}, a b$ means with different superscipts within a row are significantly different at $P \leq 0.01$ or $P \leq 0.05$ respectively

Table 5. Levels of a-tocopherol and TBARS in livers of rats

\begin{tabular}{|c|c|c|c|c|}
\hline \multirow{2}{*}{ Indices } & \multicolumn{2}{|c|}{ Group } & \multirow{2}{*}{-SE } & \multirow{2}{*}{$P$-value } \\
\hline & $\overline{\mathrm{CO}}$ & G-B $\quad$ S/C-B & & \\
\hline a-Tocopherol, $\mu \mathrm{g} \cdot \mathrm{mg}^{-1}$ & 23.89 & $24.40^{\mathrm{a}} 22.67^{\mathrm{b}}$ & 0.540 & 0.086 \\
\hline TBARS $\mathrm{nmol} \cdot \mathrm{g}^{-1}$ & 1.99 & 1. $93^{\mathrm{a}} 2.13 \mathrm{~B}^{\mathrm{b}}$ & 0.500 & 0.028 \\
\hline
\end{tabular}

CO - control diet; G-B - diet with beef from grass feeding; S/C-B - diet with beef from feeding with maize silage and concentrate; TBARS see Table 4; ${ }^{A B}$, ab means with different superscipts within a row are significantly different at $P \leq 0.01$ or $P \leq 0.05$ respectively

\section{Discussion}

Evaluation of the dietary value of modified meat is based on its chemical composition, which is an important but preliminary method of assessment. Currently, evaluation of the potential health-promoting properties of food, including milk and meat, is more often verified in human studies (McAfee et al., 2011) or with experiments with laboratory animals as models for humans (Takahashi and Ito, 2004). In the presented investigation, a preliminary experiment concerning the influence of beef cattle nutrition systems (grass vs silage/concentrate) on functional properties of the obtained meat was carried out on rats as models for humans.

The lipid profile changed as the result of experimental treatment. The beef consumed by the rats caused an elevation of TAG and total cholesterol (S/C-B group) in comparison with the control diet. This was probably the effect of the higher intake of 
SFAs and lower intake of MUFA and PUFA in beefcontaining diets. SFAs, including C 14:0 and C 16:0 in particular, contribute to increasing total serum cholesterol and LDL concentrations (Richter, 2007). Saturated acids decrease the activity of the LDL receptors that bind IDL and LDL cholesterol (Mustad et al., 1997; Idzior-Waluś et al., 2009; Bjermo et al., 2012). Therefore, the higher content of SFAs in beef fat, as compared with rapeseed oil, may have caused the increase in LDL cholesterol and total cholesterol concentrations in the rats receiving the beef-containing diets. This is supported by the significantly higher level of total cholesterol in the rats receiving $\mathrm{S} / \mathrm{C}-\mathrm{B}$ diets.

In studies on humans, Adams et al. (2010) found that people consuming SFA-rich diets, as compared with those on MUFA-rich diets, had higher concentrations of TAG and VLDL. These authors also demonstrated a positive correlation between the concentration of C 16:0 acids and triglycerides and VLDL in blood. In our studies on rats receiving beef-containing diets, a higher TAG concentration was found but also, a higher VLDL content was noted.

On the other hand, the total cholesterol concentration in the serum of the rats receiving meat from grass-fed animals was lower than in the rats fed the beef from silage/concentrate-fed bulls and did not statistically differ from that in the rats fed the control diet. The fatty-acid concentration of beef was characterized by a higher concentration of PUFA n-3 and by a lower ratio of n- $6 / n-3$ fatty acids in meat originating from grass-fed beef cattle. This might result in a decreased concentration of total cholesterol in blood (Menisink and Katan, 1992; Bitzur et al., 2009). PUFA n-3 fatty acids more strongly inhibit the synthesis of VLDL molecules in the liver and, thereby, cause a greater reduction of the blood cholesterol level (Richter, 2007). Epidemiological investigations also showed the effect of an SFArich diet increasing total cholesterol in blood plasma (Noakes and Clifton, 2000).

When analysing the influence of the beef cattle feeding system on redox status, as measured in the blood serum of the rats, we observed a tendency towards increasing concentrations of TBARS in group $\mathrm{S} / \mathrm{C}-\mathrm{B}$ in comparison with $\mathrm{CO}$, but also with G-B rats. The concentration of substances reacting with thiobarbituric acid reflects mainly the concentration of level of malondialdehyde (MDA) (LukaszewiczHussain et al., 2007), a product of polyunsaturated fatty acid degradation by reactive oxygen species. MDA concentration increase during oxidative stress; moreover, MDA may bind DNA and promote mutagenesis and cancerogenesis (Marnett, 1999;
Bastide et al., 2011). Oxidative stress appears when the ratio of PUFA to antioxidants, especially those penetrating the lipid phase of the body, is not in balance (Sies, 1997). Interestingly, the similar level of fat and even higher concentration of PUFA n-3 in the meat of grass-fed beef cattle did not increase MDA concentration (TBARS level) in rats. When considering the concentration of $\alpha$-tocopherol in meat from grass-fed cattle but also the $\alpha$-tocopherol concentration in the liver of the rats, we could hypothesize that the higher level of $\alpha$-tocopherol might scavenge reactive oxygen species and prevent fatty acid peroxidation in the rats. Also, the activity of glutathione peroxidase (GPx) in the serum of rats might point to a mechanism resulting from pasture feeding system of beef cattle that stimulates antioxidant defence in the organism of rats. GPx is a key enzyme involved in defence against oxidative stress by reducing hydrogen peroxide to water and also by its ability to reduce lipid hydroperoxides (Surapaneni and Venkataramana, 2007). Activation of GPx in the serum of the rats that were fed the grass-fed meat may result from the availability of glutathione or selenium in the body, but also of other redox-related molecules that cooperate with glutathione (Miyamoto et al., 2003). According to Jain et al. (2000), vitamin $\mathrm{E}$ may restore the glutathione concentration to typical values in human erythrocytes, which may explain our results and underscore that the activity of antioxidant enzymes is related to the availability of exogenous antioxidants in the organism.

The antioxidative status of rat organisms was determined by the applied experimental factors, oil and meats, but also by the fixed components of all diets, i.e. mineral and vitamin mixtures (Table 1). In respect to the delivery of $\alpha$-tocopherol, apart from the vitamin mixture, the rats also received it from rapeseed oil or meats used in the diets. The concentration of $\alpha$-tocopherol in the liver of rats was the highest in the group receiving meat from grass-fed beef cattle. Grass-fed beef, as compared with beef originating from animals reared in the silage/concentrate system, contained a higher level of $\alpha$-tocopherol, which was reflected in its higher intake by the experimental animals. The increase in the $\alpha$-tocopherol level in the liver along with an increasing vitamin $E$ intake with diets for rats was also reported by Farwer et al. (1994). Vitamin $\mathrm{E}$ is the most important protector against lipid peroxidation (Gröber, 2010). In the presented study, the concentration of TBARS in liver was the lowest in the G-B group of rats. The rats that were fed with grass-fed beef were characterized by a higher intake of $\alpha$-tocopherol with the diet and, simultaneously, by a lower concentration of TBARS 
assayed in their plasma and liver. A relationship between $\alpha$-tocopherol intake and lipid peroxidation has also observed by other authors (Jain et al., 2000; De Cabo et al. 2006).

\section{Conclusions}

The conducted studies indicate that consumers of beef should be aware of the origin of beef, i.e. from what nutrition system it comes. Despite the lack of significant differences in the indicators of lipid metabolism, more favourable effects of beef from grass-fed cattle, as compared with that from animals fed the concentrates, were pronounced. This was reflected in a positive effect on the selected parameters of antioxidative status of the organisms of model animals: stimulation of glutathione peroxidase activity, higher concentration of vitamin $\mathrm{E}$ and lower concentration of thiobarbituric acid-reactive substances in the liver.

\section{References}

AOAC, 2005. Association of Analytical Chemists, Official Methods of Analysis. $16^{\text {th }}$ Edition. Arlington, VA

Adams T.H., Walzem R.L., Smith D.R., Tseng S., Smith S.B., 2010. Hamburger high in total, saturated and trans-fatty acids decreases HDL cholesterol and LDL particle diameter, and increases TAG, in mildly hypercholesterolaemic men. Brit. J. Nutr. 103, 91-98.

Barton L., Marounek M., Kudrna V., Bures D., Zahradkova R., 2007. Growth performance and fatty acid profiles of intramuscular and subcutaneous fat from Limousin and Charolais heifers fed extruded linseed. Meat Sci. 76, 517-523

Bastide N.M., Pierre F.H., Corpet D.E., 2011. Heme iron from meat and risk of colorectal cancer: A meta-analysis and a review of the mechanisms involved. Cancer Prev. Res. (Plila) 4, 177-184

Bitzur R., Cohen H., Kamari Y., Shaish A., Harats D., 2009. Triglycerides and $\mathrm{HDL}$ cholesterol stars or second leads in diabetes? Diabetes Care 32, S373-S377

Bjermo H., Iggman D, Kullberg J. et al., 2012. Effects of n-6 PUFAs compared with SFAs on liver fat, lipoproteins, and inflammation in abdominal obesity: a randomized controlled trial. Amer. J. Clin. Nutr. 95, 1003-1012

De la Fuente J., Diaz M.T., Alvarez I.et al., 2009. Fatty acid and vitamin $\mathrm{E}$ composition of intramuscular fat in cattle reared in different production systems. Meat Sci. 82, 331-337

De Cabo R., Burgess J.R., Placido N., 2006. Adaptation to oxidative stress induced by vitamin $\mathrm{E}$ deficiency in rat liver. J. Bioenerg. Biomembr. 38, 309-317

Farwer S., Der Boer B.C.J., Haddeman E., Kivits G.A.A., Wiersma A., Danse B.H., Danse J.C., 1994. The vitamin E nutritional status of rats fed on diets high in fish oil, linseed oil or sunflower seed oil. Brit. J. Nutr. 72, 127-145

Fraser F., 1999. Associations between diet and cancer, ischemic heart disease, and all-cause mortality in non-Hispanic white California Seventh-Day Adventists. Amer. J. Clin. Nutr. 70, 532S-538S

Gröber U., 2010. Micronutrients. Metabolic Tuning-Prevention-Therapy (in Polish). MedPharm Polska. Wrockaw, pp. 110-115
Hu F.B., Stampfer M.J., Manson J.E., Ascherio A., Colditz G.A., Speizer F.E., 1999. Dietary saturated fats and their food sources in relation to the risk of coronary heart disease in women. Amer. J. Clin. Nutr. 70, 1001-1008

Idzior-Waluś B., Sanak M., Starzyk J., Czarnecka D., Waluś-Miarka M., 2009. Autosomal dominant hypercholesterolemia - underrecognised diagnostic and clinical problem. Kardiol. Pol. 67, 1015-1022

Jain S.K., McVie R., Smith T., 2000. Vitamin E supplementation restores glutathione and malondialdehyde to normal concentrations in erythrocytes of type 1 diabetic children. Diabetes Care 23, 1389-1394

Kontogianni M.D., Panagiotakos D.B., Pitsavos C., Chrysohoou C., Stefanadis C., 2008. Relationship between meat intake and the development of acute coronary syndromes: The CARDIO2000 case-control study. Eur. J. Clin. Nutr. 62, 171-177

Kraus R.J., Gather H.E., 1980. Reaction of cyanide with glutathione peroxidase. Biochem. Biophys. Res. Commun. 96, 1116-1122

Łozicki A., Dymnicka M., Arkuszewska E., Pustkowiak H., 2012. Effect of pasture or maize silage feeding on the nutritional value of beef. Ann. Anim. Sci. 12, 81-93

Łukaszewicz-Hussain A., Moniuszko-Jakoniuk J., Rogalska J., 2007. Assessment of lipid peroxidation in rat tissues in subacute chlorfenvinphos administration. Pol. J. Environ. Stud. 16, 233-236

Marnett L.J., 1999. Lipid peroxidation-DNA damage by malondialdehyde. Mutat. Res. 424, 83-95

McAfee A.J., McSorley E.M., Cuskelly G.J., Fearon A.M., Moss B.W., Beattie J.A., Wallace J.M., Bonham M.P., Strain J.J., 2011. Red meat from animals offered a grass diet increases plasma and platelet n-3 PUFA in healthy consumers. Brit. J. Nutr. 105, 80-89

McAfee A.J., McSorley E.M., Cuskelly G.J., Moss B.W., Wallace J.M.W., Bonham M.P., Fearon A.M., 2010. Red meat consumption: An overview of the risks and benefits. Meat Sci. $84,1-13$

Menisink R.P., Katan M.B., 1992. Effect of dietary fatty acids on serum lipids and lipoproteins. A meta-analysis of 27 trials. Arterioscler. Tromb. 12, 911-919

Miyamoto Y., Koh Y.H., Park Y.S., Fujiwara N., Sakiyama H., Misonou Y., Ookawara T., Suzuki K., Honke K., Taniguchi N., 2003. Oxidative stress caused by inactivation of glutathione peroxidase and adaptive responses. Biol. Chem. 384, 567-574

Murphy M.E., Kehrer J.P., 1987. Simultaneous measurement of tocopherol and tocopheryl guinones in tissue fractions using high-performance liquid chromatography with redox-cycling electrochemical detection. J. Chromatogr. 421, 71-82

Mustad V.A., Etherton T.D., Cooper A.D., Mastro A.M., Pearson T.A., Jonnalagadda S.S., Kris-Etherton P.M., 1997. Reducing saturated fat intake is associated with increased levels of LDL receptors on mononuclear cells in healthy men and women. J. Lipid Res. 38, 459-468

Noakes M., Clifton P.M., 2000. Changes inplasma lipids and other cardiovascular risk factors during 3 energy diets differing intotal fat and fatty acid composition. Amer. J. Clin. Nutr. 71, 706-712

Razminowicz R.H., Kreuzer M., Scheeder M.R.L., 2006. Quality of retail beef from two grass-based production systems in comparison with conventional beef. Meat Sci. 73, 351-361

Reeves P.G., 1997. Components of the AIN-93 diets as improvements in the AIN-76A diet. J. Nutr. 127, Suppl. 5, 838S-841S

Richter W.O., 2007. Disorders of Lipid Metabolism. Diagnosis and Therapy (in Polish). MedPharm Polska. Wrockaw, pp. 67-71

Sies H., 1997. Oxidative stress: Oxidants and antioxidants. Exp. Physiol. $82,291-29$ 
Simonne A.H., Green N.R., Bransby J.I., 1996. Consumer acceptability and beta-carotene content of beef as related to cattle finishing diets. J. Food Sci. 61, 1254-1256

Smart D., McCusker C.A., Lamont J.V., FitzGerald S.P., Lapin C. Temml C., 1996 Reference values for various antioxidant parameters in a normal working population. Proceedings of the XVI International Congress of Clinical Chemistry. London, Poster B548

Surapaneni K.M., Venkataramana G., 2007. Status of lipid peroxidation, glutathione, ascorbic acid, vitamin $\mathrm{E}$ and antioxidant enzymes in patients with osteoarthritis. Indian J. Med. Sci. 61, 9-14
Takahashi S., Ito Y., 2004. Evaluation of meat products from cloned cattle: biological and biochemical properties. Cloning Stem Cells 6, 165-171

Uchiyama M., Mihara M., 1978. Determination of malonaldehyde precursor in tissue by thiobarbituric acid test. Anal. Biochem. 86, 271-278

Yang A., Lanari M.C., Brewster M., Tune R.K., 2002. Lipid stability and meat color of beef from pasture and grain-fed cattle with or without vitamin E supplementation. Meat Sci. 60, 41-50 